\title{
Late hemodynamic and clinical outcomes of aortic valve replacement with the Carpentier-Edwards Perimount pericardial bioprosthesis
}

\author{
Göran Dellgren, MD \\ Tirone E. David, MD \\ Ehud Raanani, MD \\ Susan Armstrong, MSc \\ Joan Ivanov, MSc \\ Harry Rakowski, MD
}

From the Division of Cardiovascular Surgery of Toronto General Hospital and the University of Toronto, Toronto, Ontario, Canada.

The Karolinska Institute and the Swedish Institute provided financial support for $\mathrm{Dr}$ Dellgren.

Received for publication Aug 28, 2001; revisions requested Sept 28, 2001; revisions received Oct 22, 2001; accepted for publication Nov 1, 2001.

Address for reprints: Tirone E. David, MD, Division of Cardiovascular Surgery, Toronto General Hospital, 200 Elizabeth St, EN 13-222, Toronto, Ontario M5N 2C4 Canada (E-mail: tirone.david@uhn.on.ca).

J Thorac Cardiovasc Surg 2002;124:146-54

Copyright ( $(2) 2002$ by The American Association for Thoracic Surgery

$0022-5223 / 2002 \$ 35.00+0 \quad \mathbf{1 2 / 1 / 1 2 1 6 7 2}$

doi: $10.1067 / \mathrm{mtc} .2002 .121672$
Objectives: The aim of this study was to investigate the long-term clinical and hemodynamic outcomes after aortic valve replacement with the Carpentier-Edwards Perimount bioprosthesis (Edwards Lifesciences, Irvine, Calif), which has been used in our institution since 1984 .

Methods: From January 1984 to December 1995, the Carpentier-Edwards pericardial bioprosthesis was used for aortic valve replacement in 254 patients (male/ female ratio 117:137) with a mean age of 71 years (range 25-87 years). Before the operation, 216 patients (85\%) were in New York Heart Association functional class III or IV. The predominant diagnosis was aortic stenosis $(\mathrm{n}=219,86 \%)$. Associated surgical procedures included coronary artery bypass grafting in 130 cases (51\%), mitral valve replacement in 11 cases (4\%), and tricuspid or mitral valve repair in 12 cases (5\%). Previous cardiac operations had been performed in 36 cases (14\%). Follow-up was $100 \%$ complete at a mean of $60 \pm 31$ months. Univariate estimates of time-related cumulative probabilities were calculated by the Kaplan-Meier method. Multivariable adjustment was performed by Cox proportional hazards regression. Echocardiography was performed in $61 \%$ of long-term survivors.

Results: There were 11 early deaths $(4 \%)$ and 58 late deaths. Actuarial survivals at 5,10 , and 12 years were $80 \% \pm 3 \%, 50 \% \pm 8 \%$, and $36 \% \pm 9 \%$, respectively. At 12 years the freedom from cardiac death was $73 \% \pm 7 \%$, the freedom from valve-related death was $84 \% \pm 11 \%$, the freedom from valve reoperation was $83 \%$ $\pm 9 \%$, the freedom from primary tissue failure was $86 \% \pm 9 \%$, the freedom from thromboembolism was $67 \% \pm 13 \%$, and the freedom from endocarditis was $98 \% \pm$ $1 \%$. Echocardiography was performed on long-term survivors (mean follow-up $67 \pm 25$ months) and showed that transvalvular peak and mean pressure differences measured with Doppler echocardiography were $23.2 \pm 9.6$ and $12.3 \pm 4.8 \mathrm{~mm} \mathrm{Hg}$, respectively. Aortic regurgitation was found by Doppler echocardiography to be none or trivial, mild, moderate, and severe in $64 \%, 30 \%, 3 \%$, and $1 \%$ of patients, respectively. Mean left ventricular mass index was $107.2 \pm 35.3 \mathrm{~g} / \mathrm{m}^{2}(118.9 \pm 40.2$ $\mathrm{g} / \mathrm{m}^{2}$ in men and $98.8 \pm 28.8 \mathrm{~g} / \mathrm{m}^{2}$ in women) at late follow-up. One third of all patients, regardless of sex $(n=26 / 64$ women and $n=14 / 45$ men $)$, had evidence of left ventricular hypertrophy. However, our analyses indicate that the residual left ventricular hypertrophy was not caused by valve mismatch but was probably multifactorial.

Conclusion: The Carpentier-Edwards Perimount bioprosthesis has provided satisfactory clinical and hemodynamic outcome. However, at long-term follow-up about one third of the patients being investigated still had left ventricular hypertrophy examined by echocardiography. 


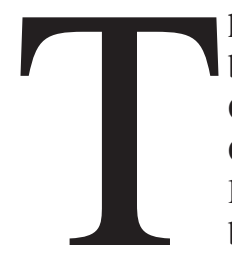

he Carpentier-Edwards Perimount (CEP) bioprosthesis (Edwards Lifesciences, Irvine, Calif) has been in clinical use since 1980 in Canada. We began using it in 1984. The long-term clinical results have previously been reported to be excellent, and this valve is regarded the bioprosthesis of choice by many surgeons. ${ }^{1-4}$ This study reviews our experience with the CEP bioprosthesis and also examines its late hemodynamic performance.

\section{Material and Methods \\ Patients}

From January 1984 to December 1995 the CEP pericardial bioprosthesis (model 2900; Edwards Lifesciences, Irvine, Calif) was used for aortic valve replacement (AVR) in 254 patients with a mean age of 71 years (range 25-87 years). The clinical profile and the operative data of these patients are summarized in Tables 1 and 2 , respectively.

From 1984 to 1989, all patients undergoing valve replacement with the CEP were discharged from the hospital with a regimen of daily warfarin sodium for the first 3 months after the operation, followed by lifelong aspirin therapy. This practice was changed in 1990, after which patients were discharged with a regimen of lifelong aspirin therapy only, with the exception of those in need of warfarin sodium for other indications, such as chronic atrial fibrillation or a concomitant mitral valve procedure.

Operative survivors were followed up by telephone or questionnaire between October 1998 and January 1999. The follow-up was $100 \%$ complete. The mean follow-up was $60 \pm 31$ months (range 1-167 months), and 1214 patient-years of follow-up were available for analysis.

\section{Doppler Echocardiography}

Transthoracic echocardiography with continuous-wave, pulsedwave, and color flow Doppler studies were performed with a Hewlett Packard 1000, 1500, 2500, or 5500 Ultrasonoscope (Hewlett-Packard Company, Palo Alto, Calif) equipped with a 2.5-MHz transducer. Sixty-one percent of survivors $(n=109 / 178)$ had an echocardiogram performed at our hospital between December 1998 and May 1999. The mean follow-up for these studies was $67 \pm 25$ months (range 7-172 months). Those patients who did not undergo echocardiography either lived too far away from the hospital or were too old and in too fragile a condition to come without great difficulty.

For further details about measurements and calculations, see the Appendix. Left ventricular hypertrophy $(\mathrm{LVH})$ was defined as a left ventricular mass index (LVMI) higher than $131 \mathrm{~g} / \mathrm{m}^{2}$ for men and higher than $100 \mathrm{~g} / \mathrm{m}^{2}$ for women. ${ }^{5}$

\section{Definitions and Statistics}

This report was based on the guidelines for reporting morbidity and mortality after cardiac valvular operations. ${ }^{6}$ Survival and time-related event analyses were performed with the Kaplan-Meier method. Multivariable analyses of risk factors for survival and time-related events were done by Cox regression methods previously described. The term actuarial survival was used to describe
TABLE 1. Clinical characteristics

\begin{tabular}{|c|c|c|}
\hline $\begin{array}{l}\text { No. of patients } \\
\text { Age }(y \text {, mean } \pm S D)\end{array}$ & $\begin{array}{r}2 \\
71.3 \pm \varepsilon\end{array}$ & $\begin{array}{l}254 \\
8.8(25-87)\end{array}$ \\
\hline Sex (No.) & & \\
\hline Male & 117 & $46 \%$ \\
\hline Female & 137 & $54 \%$ \\
\hline Electrocardiogram (No.) & & \\
\hline Sinus & 226 & $89 \%$ \\
\hline Atrial fibrillation & 17 & $7 \%$ \\
\hline Heart block & 11 & $4 \%$ \\
\hline NYHA functional classification & & \\
\hline Class I & 2 & $1 \%$ \\
\hline Class II & 36 & $14 \%$ \\
\hline Class III & 127 & $50 \%$ \\
\hline Class IV & 89 & $35 \%$ \\
\hline Aortic valve lesion & & \\
\hline Stenosis & 155 & $61 \%$ \\
\hline Insufficiency & 35 & $14 \%$ \\
\hline Mixed & 64 & $25 \%$ \\
\hline Mitral valve lesion & & \\
\hline Stenosis & 7 & $3 \%$ \\
\hline Insufficiency & 10 & $4 \%$ \\
\hline Mixed & 1 & $0.5 \%$ \\
\hline Coronary artery disease & & \\
\hline None & 126 & $50 \%$ \\
\hline 1-Vessel & 41 & $16 \%$ \\
\hline 2-Vessel & 35 & $14 \%$ \\
\hline 3-Vessel & 52 & $20 \%$ \\
\hline Left ventricular function & & \\
\hline$>0.54$ & 79 & $31 \%$ \\
\hline $0.40-0.54$ & 111 & $44 \%$ \\
\hline $0.20-0.40$ & 47 & $18 \%$ \\
\hline$<0.20$ & 5 & $2 \%$ \\
\hline Endocarditis & 12 & $5 \%$ \\
\hline Reoperation & 36 & $14 \%$ \\
\hline Previous AVR & 27 & $11 \%$ \\
\hline Previous coronary artery bypass grafting & 15 & $6 \%$ \\
\hline Previous mitral valve replacement & 2 & $1 \%$ \\
\hline Previous other & 3 & $1 \%$ \\
\hline
\end{tabular}

time-related analysis for that event and not to describe the type of analysis performed. Differences were tested for statistical significance with 1-way analysis of variance. When the $F$ test revealed a significant difference, each pair of means was compared with the Scheffé test.

\section{Results}

\section{Patient Survival}

There were 11 operative deaths (4\%). Eight of the 11 patients $(73 \%)$ had undergone combined AVR and coronary artery bypass grafting. There were 58 late deaths $(23 \%)$. Thirty-five of the 58 patients $(60 \%)$ had undergone combined AVR and coronary artery bypass grafting. Operative mortality and morbidity and late mortality are shown in Table 3. The actuarial survival is shown in Figure 1. Multivariate analysis showed that preoperative New York Heart Association (NYHA) functional class III or IV (odds ratio 
TABLE 2. Operative data

\begin{tabular}{lrl}
\hline No. of patients & \multicolumn{2}{c}{254} \\
Valve sizes implanted (mm, mean \pm SD) & $22.4 \pm 2.3$ (19-29) \\
$19 \mathrm{~mm}$ (no.) & 13 & $5 \%$ \\
$21 \mathrm{~mm}(\mathrm{no})$. & 101 & $40 \%$ \\
$23 \mathrm{~mm}(\mathrm{no})$. & 85 & $33.5 \%$ \\
$25 \mathrm{~mm}(\mathrm{no})$. & 46 & $18 \%$ \\
$27 \mathrm{~mm}$ (no.) & 8 & $3 \%$ \\
$29 \mathrm{~mm}$ (no.) & 1 & $0.5 \%$ \\
\hline Associated procedures & 130 & $51 \%$ \\
Coronary artery bypass grafting & 11 & $4 \%$ \\
Mitral valve replacement & 10 & $4 \%$ \\
Mitral valve repair & 4 & $1.5 \%$ \\
$\quad$ Tricuspid valve repair & 11 & $4 \%$ \\
$\quad$ Miscellaneous & $86.5 \pm 31.0$ (45-236) \\
\hline Aortic crossclamp time & \\
(min, mean \pm SD) & $118.4 \pm 43.1$ (61-335) \\
Cardiopulmonary bypass time (min, & \\
mean \pm SD) &
\end{tabular}

TABLE 3. Operative morbidity and mortality and late mortality

\begin{tabular}{lrr}
\hline & No. & $\%$ \\
\hline Operative morbidity & & \\
Reexploration for bleeding & 15 & 6 \\
Reexploration for cardiac arrest & 2 & 1 \\
Perioperative myocardial infarction & 7 & 3 \\
Perioperative stroke or transient ischemic attack & 10 & 4 \\
Mediastinitis & 4 & 2 \\
Permanent pacemaker implantation & 16 & 6 \\
\hline Operative mortality & 11 & 4 \\
Cardiac arrest & 2 & \\
Low cardiac output syndrome & 5 & \\
Sepsis & 2 & \\
Multiple organ failure & 1 & \\
Other & 1 & \\
\hline Late mortality & 58 & 23 \\
Valve related & 5 & \\
Stroke & 3 & \\
Endocarditis & 2 & \\
Cardiac related & 24 & \\
Congestive heart failure & 6 & \\
Myocardial infarction & 10 & \\
Sudden death & 5 & \\
Other & 3 & \\
Noncardiac & 26 & \\
Unknown & 3 & \\
\hline Total early and late deaths & $69 / 254$ & 27 \\
& &
\end{tabular}

$1.49,95 \%$ confidence interval $1.02-2.18, P=.04)$ and the presence of coronary artery disease (odds ratio 2.08 , confidence interval 1.26-3.44, $P=.004$ ) were independent risk factors for late death.
Valve-Related and Cardiac-Related Deaths

The actuarial freedoms from valve-related death at 5, 10, and 12 years were $98 \% \pm 1 \%, 96 \% \pm 2 \%$, and $84 \% \pm$ $11 \%$, respectively. The actuarial freedoms from cardiac death at 5,10 , and 12 years were $87 \% \pm 2 \%, 73 \% \pm 7 \%$, and $73 \% \pm 7 \%$, respectively.

\section{Complications}

Thromboembolism. Thromboembolic events were observed in 17 cases (14 strokes and 3 transient ischemic attacks). The freedoms from thromboembolism at 5,10, and 12 years were $93 \% \pm 2 \%, 88 \% \pm 3 \%$, and $67 \% \pm 13 \%$, respectively. The linearized rate for thromboembolic events was $1.4 \% \pm 0.1 \%$ events $/ 100$ patient-years. At the last follow-up 38 of 178 patients (21\%) were taking warfarin sodium and $140(79 \%)$ were taking aspirin daily. Multivariate analysis showed that age (odds ratio $1.11,95 \%$ confidence interval 1.02-1.20, $P=.01$ ) was an independent risk factor for thromboembolism.

Structural valve dysfunction. Structural valve deterioration occurred in 4 patients, and they were reoperated on after $8,9,9$, and 13 years of follow-up. All 4 patients had cusp tears: 2 had commissural tears and 2 had midcusp tears. In addition, 3 patients had calcification of the cusps. The actuarial freedoms from structural valve dysfunction at 5,10 , and 12 years were $100 \%, 86 \% \pm 9 \%$, and $86 \% \pm 9 \%$, respectively (Figure 2). The actual freedoms from structural valve dysfunction at the corresponding intervals were $100 \%, 92 \% \pm 6 \%$, and $92 \% \pm 6 \%$, respectively (Figure 2). There were no valve failures in patients older than 65 years.

Bioprosthetic valve endocarditis. Five patients had bioprosthetic valve endocarditis that was diagnosed at 22 days, 4 months, 6 months, 3 years, and 3.5 years after the operation. Two patients were treated with antibiotics and replacement of the bioprosthesis, after which both survived. Three patients were treated with antibiotics alone; 1 survived and 2 died. The patient who survived after treatment with antibiotics alone had only mild aortic regurgitation on echocardiography at follow-up. The actuarial freedoms from bioprosthetic valve endocarditis at 5,10 , and 12 years were $98 \% \pm 1 \%, 98 \% \pm 1 \%$, and $98 \% \pm 1 \%$, respectively.

Reoperations. Six patients underwent reoperation, and all survived. The indications for reoperation were structural valve deterioration in 4 cases and endocarditis in 2 cases. The actuarial freedoms from reoperation at 5,10 , and 12 years were $99 \% \pm 1 \%, 83 \% \pm 9 \%$, and $83 \% \pm 9 \%$, respectively.

Other complications. Only 1 patient had a serious anticoagulant-related hemorrhage, even though $21 \%$ of the patients were receiving oral anticoagulation. Four patients needed late pacemaker implantation. Eight patients had a late acute myocardial infarction. 


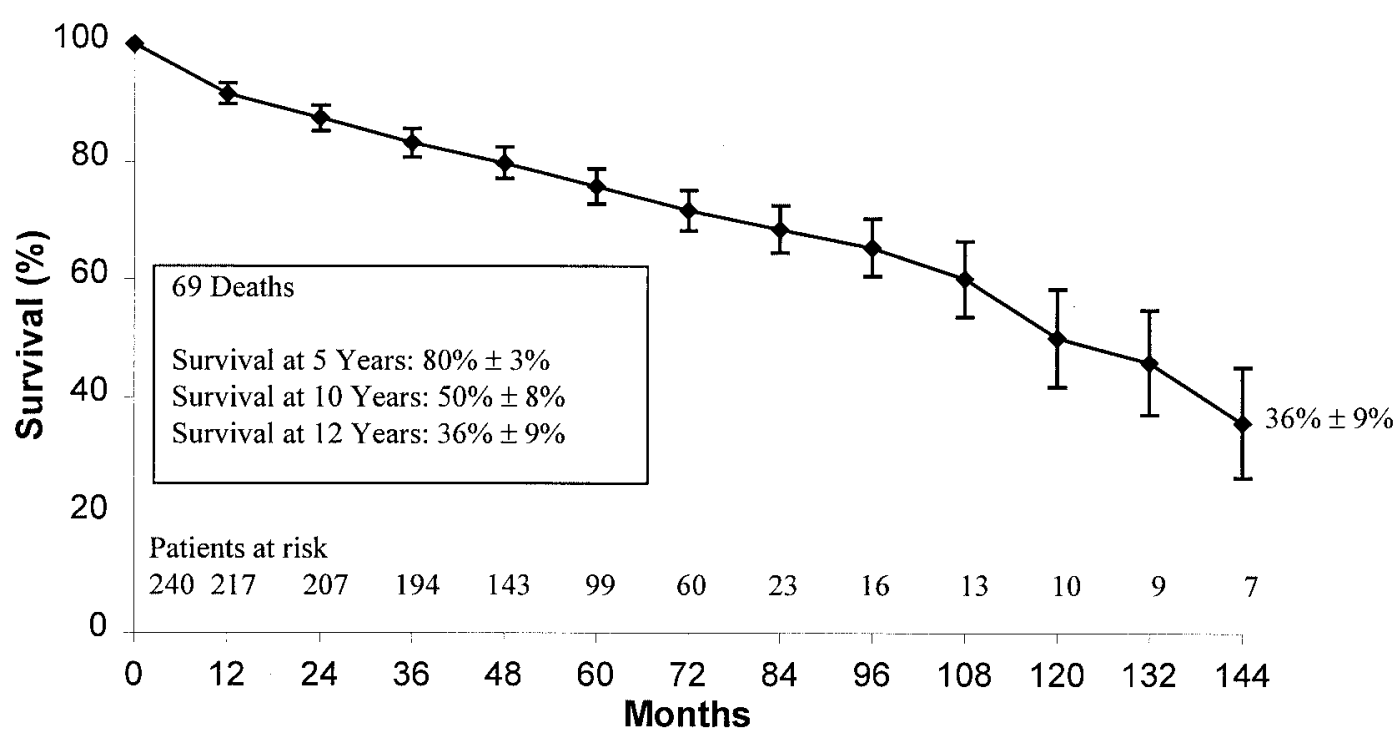

Figure 1. Actuarial survival. Data points represent mean; error bars represent SEM.

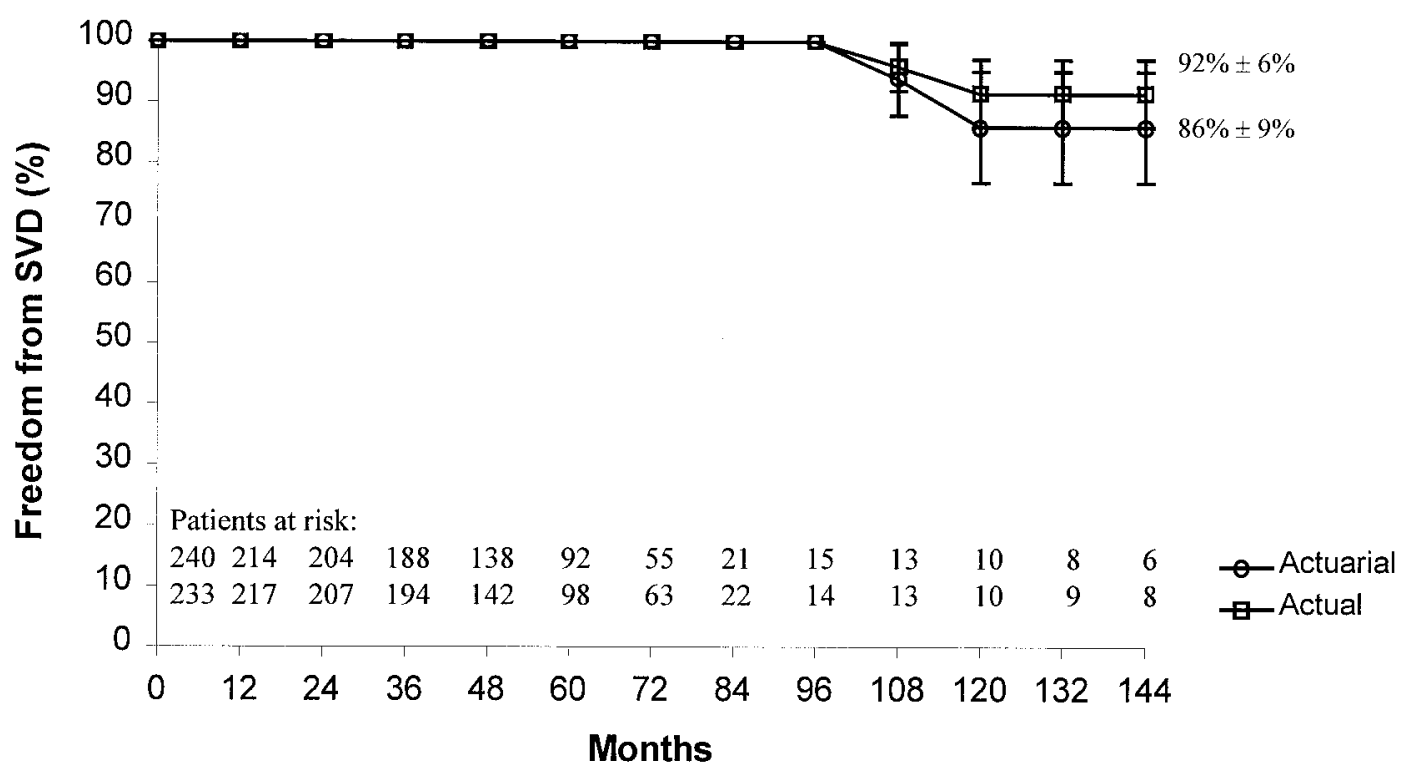

Figure 2. Actuarial (circles) and actual (squares) freedoms from structural valve degeneration (SVD).

\section{Late Functional Classification}

At the latest follow-up 178 patients were alive and had the original CEP bioprosthesis in place. Seventy-two patients $(41 \%)$ were in NYHA functional class I, $63(35.5 \%)$ were in class II, $41(23 \%)$ were in class III, and $1(0.5 \%)$ was in class IV.

\section{Echocardiography}

Echocardiography of long-term survivors (mean $67 \pm 25$ months) showed that peak and mean gradients for all valve sizes were $23.2 \pm 9.6 \mathrm{~mm} \mathrm{Hg}$ (range $11-66 \mathrm{~mm} \mathrm{Hg}$ ) and
$12.3 \pm 4.8 \mathrm{~mm} \mathrm{Hg}$ (range 5-31 mm Hg), respectively. Table 4 shows Doppler-echocardiographic data according to valve sizes at late follow-up. Smaller valves had statistically significantly higher transvalvular peak $(P=.02)$ and mean $(P=.003)$ gradients than did larger valves. Mean aortic valve area for all valves was $1.3 \pm 0.3\left(\right.$ range $0.5-2.36 \mathrm{~cm}^{2}$ ), and area increased significantly with increasing valve size $(P=.0001)$. Also, aortic valve areas were significantly larger in 27-, 25-, and 23-mm valves than in 19- and 21-mm valves (Table 4). However, 22 patients (20\%) had an aortic valve area smaller than $1 \mathrm{~cm}^{2}$ at late follow-up. 
TABLE 4. Doppler echocardiographic results of CEP aortic valve bioprosthesis according to valve size at follow-up

\begin{tabular}{|c|c|c|c|c|c|c|}
\hline $\begin{array}{l}\text { Valve } \\
\text { size } \\
(\mathrm{mm}) \\
\end{array}$ & No. of patients & $P_{\text {peak }}(\mathrm{mm} \mathrm{Hg})$ & $P_{\text {mean }}(\mathrm{mm} \mathrm{Hg})$ & $\mathrm{EOA}\left(\mathrm{cm}^{2}\right)$ & $\mathrm{CI}\left(\mathrm{L} \cdot \mathrm{min}^{-1} \cdot \mathrm{m}^{-2}\right)$ & $\mathrm{BSA}\left(\mathrm{m}^{2}\right)$ \\
\hline 19 & 5 & $38.4 \pm 17.4$ & $19.4 \pm 7.6$ & $0.95 \pm 0.2$ & $3.5 \pm 1.2$ & $1.59 \pm 0.1$ \\
\hline 21 & 45 & $24.7 \pm 10.2$ & $13.0 \pm 5.0$ & $1.1 \pm 0.2$ & $2.7 \pm 0.5$ & $1.66 \pm 0.2$ \\
\hline 23 & 33 & $21.4 \pm 7.2$ & $11.2 \pm 3.6^{*}$ & $1.5 \pm 0.3 \dagger \ddagger$ & $2.6 \pm 0.9$ & $1.82 \pm 0.1 \ddagger$ \\
\hline 25 & 22 & $20.1 \pm 7.3 \S$ & $11.2 \pm 4.3^{*}$ & $1.4 \pm 0.3 \dagger \ddagger$ & $2.4 \pm 0.7$ & $1.87 \pm 0.2 \ddagger$ \\
\hline 27 & 4 & $19.0 \pm 10.8$ & $10.1 \pm 4.5$ & $1.6 \pm 0.4 \dagger$ & $2.5 \pm 0.8$ & $1.84 \pm 0.14$ \\
\hline All sizes & 109 & $23.2 \pm 9.6$ & $12.3 \pm 4.8$ & $1.3 \pm 0.3$ & $2.7 \pm 0.7$ & $1.76 \pm 0.2$ \\
\hline
\end{tabular}

All values are expressed as mean \pm SD. Significant differences between valve sizes according to Scheffé test are indicated by symbols. $P_{p e a k}$ Maximum pressure difference; $P_{\text {mean }}$ mean pressure difference; $E O A$, effective orifice area, $C l$, cardiac index; $B S A$, body surface area.

${ }^{*} P<.05$, sizes 25 and 23 versus size $19 \mathrm{~mm}$.

$\dagger P<.05$, sizes 27,25 , and 23 versus size $19 \mathrm{~mm}$.

$\ddagger P<.05$, sizes 25 and 23 versus size $21 \mathrm{~mm}$.

$\S P<.05$, size 25 versus size $19 \mathrm{~mm}$.

M-mode Doppler measurements and calculations of left ventricular mass and LVMI are shown in Table 5. In a general linear model there were significant increases in left ventricular end-diastolic dimension $(P=.03)$ and interventricular septum $(P=.04)$ with increasing valve size. However, there was no significant difference in posterior wall measurement $(P=.42)$ with increasing valve size. The only statistically significant difference seen between valve sizes was that left ventricular end-diastolic dimension was increased in patients with $25-\mathrm{mm}$ valves relative to those with 21-mm valves (Table 5). Mean left ventricular mass and LVMI were $189.0 \pm 70.5 \mathrm{~g}$ (range $90-518 \mathrm{~g}$ ) and $107.2 \pm$ $35.3 \mathrm{~g} / \mathrm{m}^{2}$ (range $53-245 \mathrm{~g} / \mathrm{m}^{2}$, male $118.9 \pm 40.2 \mathrm{~g} / \mathrm{m}^{2}$, female $\left.98.8 \pm 28.8 \mathrm{~g} / \mathrm{m}^{2}\right)$, respectively. Left ventricular mass and LVMI increased statistically significantly with increasing valve size $(P=.0001$ and $P=.01$, respectively). Body surface area also increased significantly with increased valve size $(P=.0001)$. One third of all patients, regardless of gender (26/64 of the women and 14/45 of the men), had evidence of LVH. Valve sizes correlated for body surface area (indexed valve size) in patients with LVH were similar to those in patients without LVH (Figure 3). This suggests that valve mismatch was not the reason for $\mathrm{LVH}$ seen at long-term follow-up in this subgroup of patients. Indexed valve area stratified according to valve size showed a trend toward higher mean indexed valve sizes for larger valves, which might suggest a relative mismatch for smaller valve sizes (Figure 4). However, LVMI increased with larger valve sizes, again indicating that valve size or valve mismatch was not the final determinant of LVMI or LVH. At follow-up, 69\% (n = 75/109) had normal systolic left ventricular function, whereas $25 \%(\mathrm{n}=28 / 109)$ of the patients had mildly impaired left ventricular function, $3 \%$ ( $\mathrm{n}=3 / 109)$ had moderately impaired left ventricular function, and 3\% ( $\mathrm{n}=3 / 109)$ had severely impaired left ventricular function.
None or trivial, mild, moderate, and severe aortic insufficiencies were found in 65\% $(\mathrm{n}=71 / 109), 31 \%(\mathrm{n}=$ $34 / 109)$, $3 \%(n=3 / 109)$, and $1 \%(n=1 / 109)$ of the patients, respectively. Mitral regurgitation at follow-up was none or trivial in $28 \%$ of the patients $(\mathrm{n}=31 / 109)$, mild in $49 \%(\mathrm{n}=53 / 109)$, moderate in $19 \%(\mathrm{n}=21 / 109)$, and severe in $4 \%(n=4 / 109)$. There was no significant difference in mitral regurgitation between patients with and without preoperative coronary artery disease $(P=.3)$. Furthermore, when patients were stratified according to both preoperative aortic insufficiency and mitral regurgitation at follow-up, there was no significant difference in LVMI between groups (Figure 5). However, a trend toward higher LVMI was seen in patients with preoperative aortic insufficiency and more than mild mitral regurgitation at follow-up echocardiography.

\section{Discussion}

The use of glutaraldehyde-treated bovine pericardial valves for AVR was introduced in 1971 by Ionescu and associates. ${ }^{7}$ Those valves were at the time superior to porcine valves from a hemodynamic point of view ${ }^{8}$ but showed signs of limited durability in fatigue tests, a problem that was later confirmed clinically. ${ }^{9,10}$ The CEP aortic valve was introduced after several design changes, which included improved tissue preservation, a more flexible stent, a modified shape of the cusps, and modified tissue-mounting of the pericardium in the stent. Early clinical and hemodynamic studies showed excellent results. ${ }^{11,12}$ Several studies have shown excellent long-term durability with CEP valves, ${ }^{1-4}$ which seems to be related to a lower risk of primary tissue failure than seen with older porcine and bovine pericardial valves.

In this report of clinical and hemodynamic late outcomes after AVR with the CEP bioprosthesis, we confirm previous studies indicating good results comparable to newer porcine 


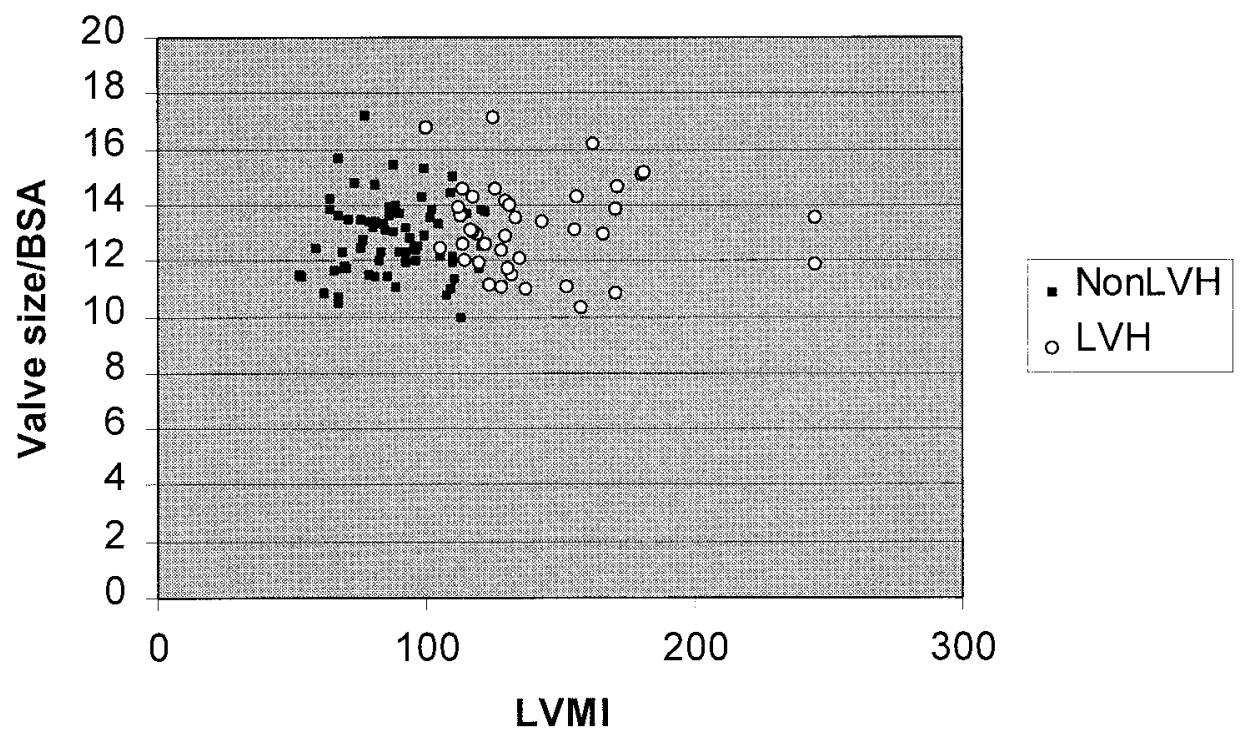

Figure 3. Valve size indexed to body surface area (BSA) and LVMI stratified for patients with (squares) and without (circles) LVH.

TABLE 5. M-mode echocardiographic results and calculations of CEP aortic valve bioprosthesis according to valve size at follow-up

\begin{tabular}{lcllllrr}
\hline Valve size $(\mathbf{m m})$ & No. of patients & LVEDD $(\mathbf{m m})$ & IVS $(\mathbf{m m})$ & PW $(\mathbf{m m})$ & LVM $(\mathbf{g})$ & LVMI $\left(\mathbf{g} / \mathbf{m}^{2}\right)$ & LVH $(\mathbf{N o})$. \\
\hline 19 & 5 & $41.0 \pm 10.9$ & $13.1 \pm 1.9$ & $10.5 \pm 1.5$ & $166.6 \pm 69.7$ & $103.2 \pm 35.5$ & $2(40 \%)$ \\
21 & 45 & $42.1 \pm 6.0$ & $11.6 \pm 2.6$ & $10.3 \pm 2.2$ & $161.1 \pm 51.8$ & $97.0 \pm 29.4$ & $14(31 \%)$ \\
23 & 33 & $45.6 \pm 5.9$ & $12.6 \pm 2.2$ & $10.4 \pm 1.8$ & $192.2 \pm 53.7$ & $105.7 \pm 28.0$ & $11(33 \%)$ \\
25 & 22 & $49.1 \pm 9.4^{*}$ & $13.7 \pm 3.3$ & $11.1 \pm 1.9$ & $243.4 \pm 94.2^{*}$ & $129.7 \pm 46.0^{*}$ & $11(50 \%)$ \\
27 & 4 & $44.4 \pm 3.6$ & $13.8 \pm 3.8$ & $11.8 \pm 1.7$ & $219.2 \pm 76.1$ & $119.7 \pm 43.1$ & $2(50 \%)$ \\
\hline All sizes & 109 & $44.6 \pm 7.4$ & $12.5 \pm 2.7$ & $10.5 \pm 2.0$ & $189.0 \pm 70.5$ & $107.2 \pm 35.3$ & $40(37 \%)$
\end{tabular}

All values are expressed as mean $\pm \mathrm{SD}$. (Significant differences between valve sizes according to Scheffé test are indicated by symbols.) $L V E D D$, Left ventricular end-diastolic dimension; IVS, interventricular septum; PW, posterior wall; $L V M$, left ventricular mass; $L V M I$, left ventricular mass index; $L V H$, left ventricular hypertrophy.

${ }^{*} P<.05$, size 25 versus size $21 \mathrm{~mm}$.

valves. ${ }^{2,3,13}$ Banbury and associates ${ }^{2}$ and Neville and associates $^{4}$ reported similar 5- and 10-year survivals, although in somewhat younger patient populations than in our study, for the CEP bioprosthesis in the aortic position. Table 6 shows survivals and freedoms from structural valve degeneration in earlier reported studies of the CEP pericardial bioprosthesis. Poirier and coworkers ${ }^{3}$ have reported excellent survival rates in a younger patient population than ours. Survivals for our patient population with the CEP bioprosthesis were lower than in our population with the Hancock II porcine bioprosthesis. ${ }^{13}$ However, our patients with the CEP bioprosthesis were significantly older than those with the Hancock II porcine bioprosthesis (Table 6). We have previously shown that advanced age, male sex, advanced left ventricular dysfunction, coronary artery disease, and advanced NYHA functional class are independent predictors of mortality among patients with AVR. ${ }^{14}$ Our patient pop- ulation was in general older and had more coronary artery disease than in other studies. ${ }^{1-4,11,13}$ Considering the risk factor profile in our study, the survival must be considered satisfactory. As anticipated, the multivariate analysis from our study showed that coronary artery disease and NYHA class III or IV were risk factors for late death and for cardiac non-valve-related death.

Our study confirms that the CEP bioprosthesis is associated with a low incidence of structural valve dysfunction comparable to earlier reports ${ }^{1-4}$ (Table 6). In our population, no patient older than 65 years has required reoperation because of structural valve degeneration. Some authors have even indicated that the CEP bioprosthesis may be superior to stented porcine bioprostheses in terms of structural valve dysfunction. ${ }^{2}$ When the CEP valve is compared with the Hancock II, a second-generation porcine aortic valve, however, the risk of degeneration appears to be 


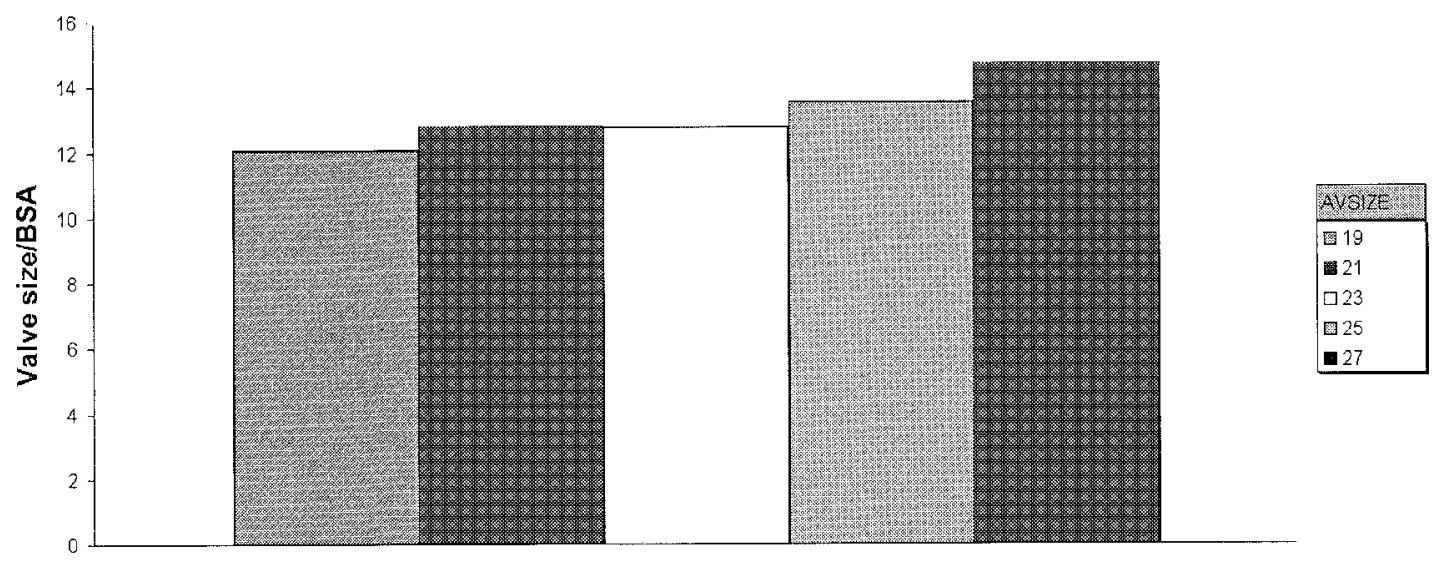

Valve size

Figure 4. Mean valve size indexed to body surface area (BSA) for all aortic valve sizes. Darkest shading, $27 \mathrm{~mm}$; second darkest, 21 mm; median shading, 19 mm; second lightest, 25 mm; lightest, 23 mm.

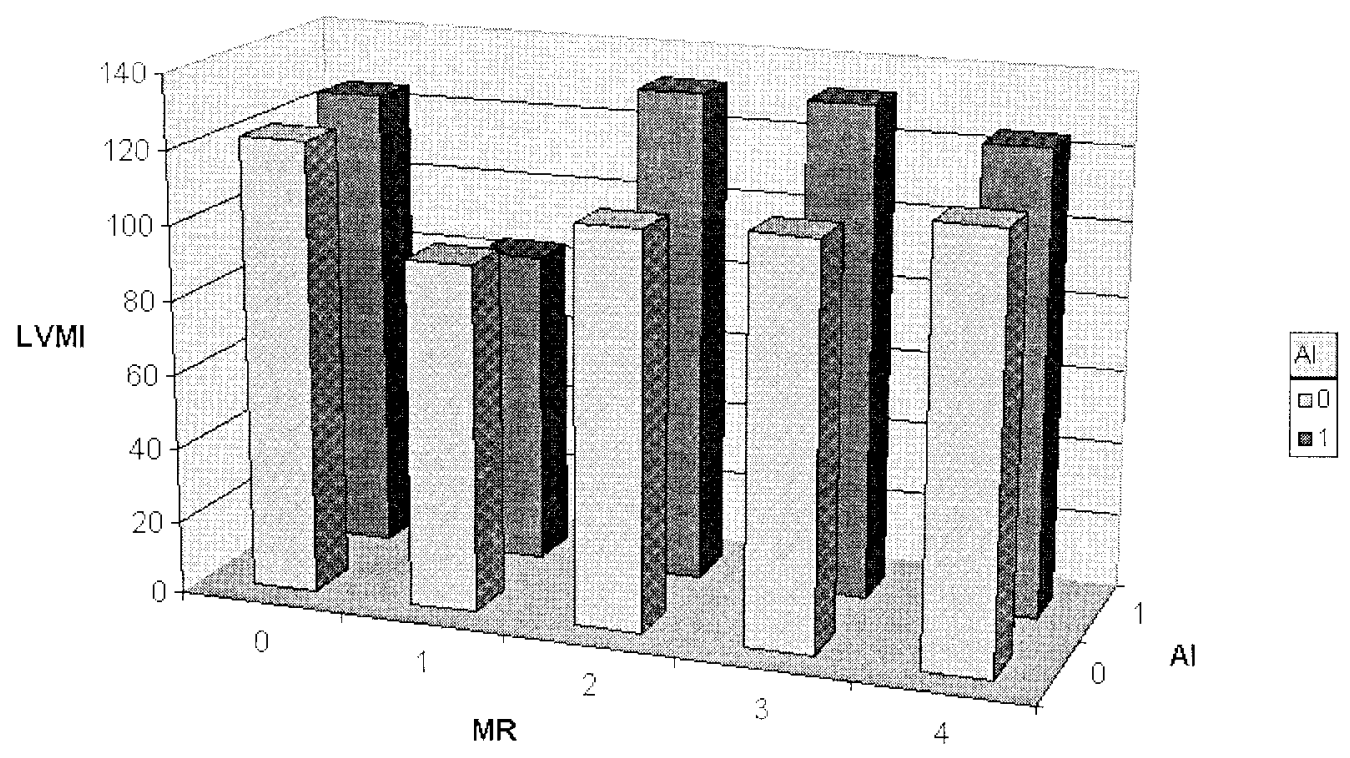

Figure 5. LVMI stratified for preoperative aortic insufficiency (AI) and mitral regurgitation (MR) on follow-up echocardiogram. Dark bars, Aortic insufficiency value of 1; light bars, aortic insufficiency value of 0.

similar. In our experience the Hancock II was used in a younger patient population, and the freedom from valve degeneration was similar to that of the CEP valve. The clinical and hemodynamic data of the CEP and Hancock II valves are similar according to our experience. ${ }^{15}$ Transvalvular gradients and aortic valve areas for the CEP appear to be slightly worse than those of the Hancock II according to retrospective studies. However, neither of these valves has as good hemodynamic data as the Toronto SPV or the Freestyle bioprosthesis. ${ }^{16,17}$ There are a few long-term reports with echocardiography on the CEP. Frater and co- workers ${ }^{11}$ reported aortic valve areas somewhat similar to those found in our study after a mean follow-up of 67 months.

We found that LVH was still present at long-term follow-up in about a third of the patients. In contrast, as previously reported by our group, ${ }^{16}$ only $8 \%$ of the patients with a Toronto SPV had LVH by echocardiography after a similar mean follow-up of 5 years. However, we have also showed that sex, hypertension, cause of valve disease, and presence of coronary artery disease, ${ }^{16}$ as well as genetic factors, ${ }^{18}$ influence both the preoperative degree of LVH 
TABLE 6. Survival and structural valve degeneration data for CEP bioprosthesis

\begin{tabular}{|c|c|c|c|c|c|c|c|c|}
\hline \multirow[b]{2}{*}{ Reference } & \multirow{2}{*}{$\begin{array}{c}\text { No. of } \\
\text { patients }\end{array}$} & \multirow[b]{2}{*}{ Mean age $(y)$} & \multicolumn{3}{|c|}{ Survival } & \multicolumn{3}{|c|}{$\begin{array}{c}\text { Freedom from structural valve } \\
\text { degeneration }\end{array}$} \\
\hline & & & $5 y$ & $10 y$ & 12 y & $5 y$ & $10 y$ & $12 y$ \\
\hline \multicolumn{9}{|c|}{ Pericardial (Carpentier-Edwards) } \\
\hline Pellerin et al, ${ }^{1} 1995$ & 124 & $64.9 \pm 13.6$ & & & $50 \% \pm 7 \%$ & $100 \%$ & $100 \%$ & $100 \%$ \\
\hline Banbury et al, ${ }^{2} 1998$ & 310 & $64.2 \pm 10.8$ & $83 \% \pm 2 \%$ & $47 \% \pm 3 \%$ & $34 \% \pm 3 \%$ & $100 \%$ & $91 \% \pm 3 \%$ & $82 \% \pm 4 \%$ \\
\hline Poirier et al, ${ }^{3} 1998$ & 812 & 64 & $80 \% \pm 2 \%$ & $69 \% \pm 3 \%$ & $68 \% \pm 3 \%$ & $99 \% \pm 0.5 \%$ & $93 \% \pm 2 \%$ & $80 \% \pm 5 \%$ \\
\hline Neville et al, 41998 & 787 & $68.3 \pm 10.8$ & & & $53 \% \pm 0.5 \%$ & $99 \% \pm 1 \%$ & $94 \% \pm 4 \%$ & $94 \% \pm 4 \%$ \\
\hline Current study & 254 & $71.3 \pm 8.8$ & $80 \% \pm 3 \%$ & $50 \% \pm 8 \%$ & $36 \% \pm 9 \%$ & $100 \%$ & $86 \% \pm 9 \%$ & $86 \% \pm 9 \%$ \\
\hline \multicolumn{9}{|l|}{ Porcine (Hancock II) } \\
\hline David et al, ${ }^{13} 1998$ & 723 & $65 \pm 12$ & $79 \% \pm 2 \%$ & $61 \% \pm 3 \%$ & $54 \% \pm 4 \%$ & $100 \%$ & $97 \% \pm 1 \%$ & $94 \% \pm 2 \%$ \\
\hline
\end{tabular}

Data are mean \pm SD when available.

and its regression. Thus many confounding factors exists between the previously mentioned studies, which makes it difficult to safely conclude anything regarding the degree of $\mathrm{LVH}$ at late follow-up. Maybe the most surprising finding of the late follow-up echocardiography was that $23 \%$ of the patients had moderate or severe mitral regurgitation. However, we were not able to show that either mitral regurgitation or preoperative aortic insufficiency was significantly more common among patients with LVH than among those without LVH.

\section{Limitations of the Study}

This study was retrospective, and therefore the valve-related complication rates were probably underestimated because follow-up was only obtained once for this population. However, the follow-up was $100 \%$ complete and reliable with respect to survival, reoperation, and echocardiographic data. The last, however, must be interpreted with caution, because the analysis was performed retrospectively and only included about $60 \%$ of the population who were alive at the time of the study.

We are grateful to Drs C.M. Feindel, R.D. Weisel, H.E. Scully, C.M. Peniston, B.S. Goldman, R.J. Baird, and L.L. Mickelborough for allowing us to use their patients' data for this study.

\section{References}

1. Pellerin M, Mihaileanu S, Couëtil JP, Relland JY, Deloche A, Fabiani $\mathrm{JN}$, et al. Carpentier-Edwards pericardial bioprosthesis in aortic position: long-term follow-up 1980 to 1994. Ann Thorac Surg. 1995;60(2 Suppl):S292-5.

2. Banbury MK, Cosgrove DM, Lyric BW, Smedira NG, Sabik JF, Saunders CR. Long-term results of the Carpentier-Edwards pericardial aortic valve: a 12-year follow-up. Ann Thorac Surg. 1998;66:S73-6.

3. Poirier NC, Pelletier CL, Pellerin M, Carrier M. 15-year experience with the Carpentier-Edwards pericardial bioprosthesis. Ann Thorac Surg. 1998;66(6 Suppl):S57-61.

4. Neville PH, Aupart MR, Diemont FF, Sirinelli AL, Lemoine EM, Marchand MA. Carpentier-Edwards pericardial bioprosthesis in aortic or mitral position: a 12-year experience. Ann Thorac Surg. 1998;66(6 Suppl):S143-7.
5. Levy D, Savage DD, Garrison RJ, Andersson KM, Kannel WB, Castelli WP. Echocardiographic criteria for left ventricular hypertrophy: the Framingham heart study. Am J Cardiol. 1987;59:956-60.

6. Edmunds LH, Clark RE, Cohn LH, Grunkemeier GL, Miller DC, Weisel RD. Guidelines for reporting morbidity and mortality after cardiac valvular operations. Eur J Cardiothorac Surg. 1996;10:812-6.

7. Ionescu MI, Tandon AP, Mary DA, Abid A. Heart valve replacement with the Ionescu-Shiley pericardial xenograft. J Thorac Cardiovasc Surg. 1977;73:31-42.

8. Becket RM, Strom J, Frischman W, Oka Y, Lin YT, Yellin EL, et al. Hemodynamic performance of the Ionescu-Shiley valve prosthesis. J Thorac Cardiovasc Surg. 1980;80:613-20.

9. Gabbay S, Bortolotti V, Wasserman F, Factor S, Strom J, Frater RW. Fatigue-induced failure of the Ionescu-Shiley pericardial xenograft in the mitral position: in vivo and in vitro correlation and a proposed classification. J Thorac Cardiovasc Surg. 1984;87:836-44.

10. Walley VM, Keon WJ. Patterns of failure in Ionescu-Shiley bovine pericardial bioprosthetic valves. J Thorac Cardiovasc Surg. 1987;93: 925-33.

11. Frater RW, Salomon NW, Rainer WG, Cosgrove DM, Wickman E. The Carpentier-Edwards pericardial aortic valve: intermediate results. Ann Thorac Surg. 1992;53:764-71.

12. Cosgrove DM, Lytle BW, Williams GW. Hemodynamic performance of the Carpentier-Edwards pericardial valve in the aortic position in vivo. Circulation. 1985;72 Suppl 2:II146-52.

13. David TE, Armstrong S, Sun Z. The Hancock II bioprosthesis at 12 years. Ann Thorac Surg. 1998;66(6 Suppl):S95-8.

14. Fremes SE, Goldman BS, Ivanov J, Weisel RD, David TE, Salerno T. Valvular surgery in the elderly. Circulation. 1989;80 Suppl 1:I77-90.

15. David TE, Armstrong S, Sun Z. Clinical and hemodynamic assessment of the Hancock II bioprosthesis. Ann Thorac Surg. 1992;54:661-8.

16. Dellgren G, David TE, Raanani E, Bos J, Ivanov J, Rakowski H. The Toronto SPV: hemodynamic data at 1 and 5 years' postimplantation. Semin Thorac Cardiovasc Surg. 1999;11(4 Suppl 1):107-13.

17. Doty DB, Cafferty A, Cartier P, Huysmans HA, Kon ND, Krause AH, et al. Aortic valve replacement with Medtronic Freestyle bioprosthesis: 5-year results. Semin Thorac Cardiovasc Surg. 1999;11(4 Suppl 1):35-41.

18. Dellgren G, Eriksson MJ, Blange I, Brodin LA, Radegran K, Sylven C. Angiotensin-converting enzyme gene polymorphism influences degree of left ventricular hypertrophy and its regression in patients undergoing operation for aortic stenosis. Am J Cardiol. 1999;84:909-13.

\section{Appendix}

\section{Doppler Echocardiography}

Color flow Doppler echocardiography was used to assess aortic insufficiency in the parasternal long-and short-axis views and in the apical 5- and 3-chamber views. Two-dimensional guided and 
stand-alone continuous-wave Doppler modes were used to interrogate flow through the aortic valve from multiple positions. Pulsed-wave Doppler was used to assess flow in the left ventricular outflow tract (LVOT).

The peak $\left(V A V_{\max }\right)$ and mean $\left(V_{A} V_{\text {mean }}\right)$ systolic flow velocities (in meters per second) across the aortic valve were recorded with continuous-wave Doppler, and those proximal to the aortic valve in the LVOT ( $V L V O T_{\max }$ and $V L V O T_{\text {mean }}$ ) were recorded with pulsedwave Doppler. The average of three consecutive cardiac cycles in sinus rhythm or of 10 cardiac cycles in atrial fibrillation was used to calculate transaortic velocities and velocity time integrals $\left(V T I_{A V}\right.$ and $V T I_{L V O T}$, in centimeters). Peak ( $P_{L V O T}$ peak and $\left.P_{A V_{\text {peak }}}\right)$ and mean $\left(P_{A V_{\text {mean }}}\right.$ and $\left.P_{L V O T}{ }_{\text {mean }}\right)$ pressure differences (in millimeters of mercury) were calculated according to the modified Bernoulli equation ${ }^{1}$ :

$$
\begin{gathered}
\mathrm{P}_{\text {peak }}=4 \times\left(\mathrm{VAV}_{\text {max }}{ }^{2}-\mathrm{VLVOT}_{\text {max }}{ }^{2}\right) \\
\mathrm{P}_{\text {mean }}=\mathrm{PAV}_{\text {mean }}-\mathrm{PLVOT}_{\text {mean }} \\
\mathrm{PAV}_{\text {mean }}-\mathrm{PLVOT}_{\text {mean }}=4 \times\left(\mathrm{VAV}_{\text {mean }^{2}}{ }^{2}-\mathrm{VLVOT}_{\text {mean }}{ }^{2}\right)
\end{gathered}
$$

The LVOT diameter ( $D$, in centimeters) was determined in midsystole from the parasternal long-axis view. The effective orifice area (EOA, in centimeters) was calculated with the continuity equation ${ }^{1}$ :

$$
\operatorname{EOA}\left(\mathrm{cm}^{2}\right)=3.14 \times 2 \mathrm{D} / 4 \times \mathrm{VTI}_{\mathrm{LVOT}} / \mathrm{VTI}_{\mathrm{AV}}
$$

Cardiac output ( $C O$, in liters per minute) was calculated as the product of stroke volume and heart rate $(H R \text {, in beats/min })^{1}$ :

$$
\mathrm{CO}=\mathrm{HR} \times\left(3.14 \times 2 \mathrm{D} / 4 \times \mathrm{VTI}_{\mathrm{LVOT}}\right) / 1000
$$

Measurements of interventricular septum (IVS) and posterior wall $(P W)$ thicknesses (in centimeters) and left ventricular enddiastolic dimension ( $L V E D D$, in centimeters) were obtained with 2-dimensional echocardiography in a standard fashion. Left ventricular mass ( $L V M$, in grams) was calculated from IVS and PW thicknesses and the LVEDD according to the American Society of Echocardiography cube method ${ }^{2}$ :

$$
\begin{aligned}
\mathrm{LVM}= & 0.8 \times 1.04 \times\left[(\mathrm{IVS}+\mathrm{PW}+\mathrm{LVEDD})^{3}\right. \\
& \left.-(\mathrm{LVEDD})^{3}\right]+0.6
\end{aligned}
$$

The left ventricular mass index was calculated by dividing LVM by body surface area.

Aortic insufficiency was assessed with color flow Doppler and CW and PW Doppler in any view. ${ }^{3}$ The ejection fraction was determined according to the Simpson rule and left ventricular function was classified by ejection fraction as grade $1(>60 \%)$, grade $2(40 \%-60 \%)$, grade $3(20 \%-40 \%)$, or grade $4(<20 \%){ }^{1}$

\section{References}

1. Feigenbaum H. Hemodynamic information derived from echocardiography. In: Feigenbaum H, editor. Echocardiography. 5th ed. Philadelphia: Lea \& Febiger; 1994. p. 138-40, 181-215.

2. Devereux RB, Alonso DR, Lutas EM, Gottlieb GJ, Campo E, Sachs I, et al. Echocardiographic assessment of left ventricular hypertrophy: comparison to necropsy findings. Am J Cardiol. 1986:57:450-8.

3. Perry GJ, Helmcke F, Nanda NC, Byard C, Soto B. Evaluation of aortic insufficiency by Doppler color flow mapping. J Am Coll Cardiol. 1987;9:952-9. 